\title{
LEITURAS DO MARANHÃO: UMA PROPOSTA DE ENSINO DE LITERATURA A PARTIR DE TEXTOS DE AUTORES MARANHENSES EM UMA ESCOLA DE ENSINO MÉDIO DE TIMON (MA)
}

\author{
LEITURAS DO MARANHÃO: A PROPOSAL FOR TEACHING LITERATURE BASED \\ ON TEXTS BY MARANHÃO AUTHORS AT A HIGH SCHOOL FROM TIMON (MA)
}

Recebido: 23/09/2020 Aprovado: 04/01/2021 Publicado: 10/01/2021

DOI: $10.18817 /$ rlj.v4i02.2386

\author{
Rhusily Reges Lira ${ }^{1}$ \\ Orcid id: https://orcid.org/0000-0002-2307-3507 \\ Natércia Moraes Garrido 2 \\ Orcid id: https://orcid.org/0000-0002-5070-3383
}

\begin{abstract}
Resumo: Este trabalho tem por objetivo apresentar os resultados efetivos advindos do Projeto de Extensão Leituras do Maranhão: uma proposta de ensino de Literatura a partir de_textos de autores maranhenses em uma escola de Ensino Médio de Timon (MA). O desenvolviménto deste projeto abrange o período de 01 de setembro de 2016 a 31 de agosto de 2017 e ele objetiva ampliar, por meio da leitura e interpretação de textos poéticos de autores maranhenses, o poder de argumentação crítica oral e escrita de alunos do $2^{\circ}$ ano do Ensino Médio de uma escola estadual pertencente ao município de Timon - MA. A justificativa para a execução do projeto é que, por estar localizada entre dois estados brasileiros (Maranhão e Piaú), a cidade de Timon demonstra pouca identidade com a cultura maranhense. Como consequência desta localização geográfica, os alunos timonenses secundaristas revelam conhecer mais sobre a cultura do Piauí do que a do Maranhão. A metodologia de trabalho adotada volta-se para a prática de ensino de literatura visando a formação do pensamento crítico do aluno.
\end{abstract}

Palavras-chave: Ensino de Literatura. Pensamento crítico. Ensino Médio. Literatura Maranhense. Poesia.

Abstract: This work aims to present the effective results of the Leituras do Maranhão Extension Project: a proposal to teach Literature from texts by Maranhão authors in a Timon High School (MA). The development of this project covers the period from September 1st, 2016 to August 31st, 2017 and aims to expand, through reading and interpretation of poetic texts by Maranhão authors, the power of oral and written critical argumentation of students of the 2nd year of high school in a state school belonging to the municipality of Timon - MA. The justification for the execution of the project is that, being located between two Brazilian states (Maranhão and Piauí), the city of Timon demonstrates little identity with the culture of Maranhão. As a consequence of this geographical location, the Timon secondary students reveal to know more about the culture of Piauí than that of Maranhão. The work methodology adopted turns to the practice of teaching literature aiming at the formation of the student's critical thinking.

\footnotetext{
${ }^{1}$ Mestranda em Letras área de concentração em Literatura pelo Programa de Pós-Graduação em Letras da Universidade Federal do Piauí - UFPI; Graduada em Letras - Português pela Universidade Estadual do Maranhão - UEMA. É integrante do Núcleo de Pesquisa em Literatura e Linguagem LITERLI e do Núcleo de Estudos em Neorregionalismo, Imaginário e Narratividade - NENIN. E-mail: rhusily19@gmail.com

2 Graduação em Letras Português/ Inglês e Respectivas Literaturas pela Universidade Estadual do Maranhão - UEMA (2003). Mestre em Literatura e Crítica Literária pela PUC-SP (2016). Doutoranda em Literatura e Crítica Literária pela PUC-SP (2019-2023). Professora de Língua Inglesa e Língua Portuguesa do Instituto Federal do Maranhão Campus Caxias (MA); Professora na Universidade Estadual do Maranhão - UEMA Campus Caxias (MA). E-mail: naterciagarr@gmail.com
} 
Keywords: Literature teaching. Critical thinking. High School. Maranhense literature. Poetry.

\section{Introdução}

Este projeto tem origem no pensamento de Antônio Candido (2011, p.176) a respeito da real função da literatura em nossas vidas: todos têm direito à literatura e dessa forma ela deve estar inserida em nosso cotidiano:

Não há povo e não há homem que possa viver sem ela, isto é, sem a possibilidade de entrar em contato com alguma espécie de fabulação. Assim como todos sonham todas as noites, ninguém é capaz de passar as vinte e quatro horas do dia sem alguns momentos de entrega ao universo fabulado.

Analisando esse pensamento e percebendo que todos nós necessitamos de um pouco de imaginação em nossa rotina, chegamos à conclusão de que a arte literária é algo intrínseco à vida humana, é algo indispensável para a alma.

O trabalho docente feito a partir da leitura literária, de forma crítica, é necessário tanto na escola como em outros ambientes; é por meio dele que podemos conhecer e compreender o mundo em que vivemos. A leitura literária educa social e culturalmente nossos alunos e, sendo assim, o presente projeto foi elaborado com o intuito de promover aulas diferenciadas para o ensino de literatura no Ensino Médio em uma escola no município de Timon/MA, pois percebemos que o ensino de literatura ainda tende a priorizar práticas docentes tradicionais, a exemplo do uso da historiografia e memorização de datas, principais obras e estilos literários. Toda essa prática se direciona apenas para um conhecimento memorizável e quantitativo.

É visível a dificuldade que alguns professores sentem ao trabalhar a literatura em sala de aula, por isso priorizam tanto as questões históricas e biográficas; mas trabalhar o texto literário com os alunos envolvendo-os de forma prazerosa e dinâmica torna a aula muito mais proveitosa e satisfatória para todos. O trabalho com um ensino literário focado na formação do pensamento crítico vem sendo bastante discutido por vários autores que, por meio de suas pesquisas, apresentam sugestões metodológicas diferenciadas e mais estimulantes, deixando de lado a tradicionalmente explorada historicidade literária nas aulas de literatura.

Entendemos que este ensino tradicional despreza o saber crítico dos alunos por não permitir que eles exponham suas reflexões acerca do texto lido. Para mudar esse cenário, é necessário que os alunos tenham contato com os textos literários e, de preferência, aqueles que veiculam a literatura de nosso estado: o Maranhão. Por 
meio de observações prévias, constatamos que a literatura maranhense é pouco utilizada em sala de aula.

Isso se deve em grande parte à localização geográfica do munícipio de Timon (MA), situado a leste do Estado do Maranhão e ao mesmo tempo às margens do rio Parnaíba, do lado da capital piauiense Teresina. Ou seja, a cidade se encontra em uma zona de transição entre dois Estados brasileiros. A proximidade com uma capital pode ser vista como positiva por vários motivos, como o acesso às facilidades econômicas por exemplo. Porém no âmbito cultural isso só prejudica, pois impõe uma identidade que não reflete o estado do Maranhão.

O ensino de literatura que não se aplica ao cotidiano e que não se preocupa com a formação do aluno enquanto sujeito crítico tem suas consequências e uma delas é apontada por Rildo Cosson (2014, p.15):

\begin{abstract}
O estreitamento do espaço da literatura na escola e, consequentemente, nas práticas leitoras das crianças e jovens. No campo do saber literário, o efeito de tal estreitamento pode ser potencialmente ainda mais desastroso porque a escola é a instituição responsável não apenas pela manutenção e disseminação de obras consideradas canônicas, mas também de protocolos de leituras que são próprias da leitura. Se a presença da literatura é apagada da escola, se o texto literário não tem mais lugar na sala de aula, desaparecerá também o espaço da literatura como lócus de conhecimento.
\end{abstract}

Dessa forma as aulas de Língua Portuguesa devem ser voltadas, especialmente, para o texto literário como prática de leitura e a formação do pensamento crítico e apresentando a literatura como necessidade básica do ser humano para aguçar a percepção diante das coisas do mundo.

Diante do que foi ora exposto, propomos nesse trabalho apresentar as etapas desenvolvidas e os resultados obtidos do projeto de extensão universitária aplicado ao ensino literário, cujo objetivo foi ampliar, por meio da leitura e interpretação de textos literários, o poder de argumentação crítica oral e escrita de alunos do Ensino Médio em uma escola da rede estadual do munícipio de Timon - MA. Optamos por selecionar textos poéticos de autores maranhenses, valorizando desta forma a cultura do nosso estado. O projeto foi contemplado e desenvolvido por meio do Programa Institucional de Bolsa de Extensão - PIBEX, vinculado à Universidade Estadual do Maranhão (Brasil) e teve duração de onze meses (iniciou-se em setembro de 2016 e finalizou em agosto de 2017.)

Os textos que foram trabalhados no projeto tinham como tema a cultura maranhense, pois a cultura é a representação da identidade de um povo e como o 
nosso objetivo era inserir a cultura maranhense no cotidiano escolar dos alunos, optamos por fazer isso com a literatura, pois "sabemos que a literatura não é uma forma comum de lazer, mas sim uma forma de entrar na cultura." (COSSON, 2014, p.20).

A seleção das obras literárias abordadas no projeto foi feita com certo cuidado, pois optamos por trabalhar com o gênero lírico para desmitificar o pensamento que há na cabeça dos alunos de que poesia trata apenas de assuntos amorosos. Trabalhamos com poemas maranhenses modernos e contemporâneos, publicados a partir da década de 1940. É importante dizer que o Modernismo enquanto estética literária chegou ao Maranhão tardiamente, porém quando se consolidou nos debates acadêmicos, mudou completamente o que se entendia por literatura e arte. Segundo Rossini Corrêa (2015, p.60):

\begin{abstract}
A partir da segunda metade do século XX - período pós-guerra, em que, de um modo geral, pode-se observar, na literatura, em primeiro plano, a ficção regionalista, o ensaio social e o aprofundamento da lírica moderna, oscilando entre o fechamento e a abertura do eu à sociedade, à natureza precisamente dos anos 60, 70, entretanto, é que a intelectualidade, a expressão artístico-literária maranhense vai ganhando novos timbres e tonalidades, na composição de uma literatura engajada, configurando-se e revelando, numa consonância com o momento histórico, a realidade sóciopolítica então vigente no País.
\end{abstract}

Observando toda essa contextualização sobre como ocorre o início do Modernismo no Maranhão, podemos perceber que a escolha das temáticas que fizemos insere-se na gênese moderna maranhense, a qual reflete simplesmente suas questões socioculturais. Os poemas modernistas e contemporâneos de nosso Estado retratam o sujeito enquanto um ser social, totalmente consciente de seu pertencimento cultural e livre para agir, até porque os poetas dessa época se preocuparam em reafirmar a identidade deste sujeito. Dessa geração destacamos os nomes de Ferreira Gullar, Dagmar Desterro, Bandeira Tribuzi e Nascimento Moraes Filho.

\title{
Metodologia de trabalho
}

Propõe-se neste projeto uma metodologia de trabalho que atualize de forma crítica o ensino de Literatura no Ensino Médio, utilizando como base os pressupostos teóricos de Cosson (2006) e a sequência didática sugerida por ele a fim de formar o pensamento crítico do aluno por meio das aulas de Literatura. Acrescido a este intento, procuramos valorizar a cultura maranhense por meio da proposta de leitura de textos 
de autores literários maranhenses. Para tanto, o projeto iniciou com a leitura de textos teóricos sobre o assunto; em seguida, foi elaborada uma ficha de observação das aulas de Literatura a fim de se analisar a qualidade do ensino de Língua Portuguesa na escola pública estadual selecionada, que foi a Escola Militar Tiradentes.

A princípio, elaborou-se e aplicou-se um questionário com duas professoras de Língua Portuguesa a fim de se entender suas metodologias de trabalho. Nesta etapa constatou-se o esperado: que o ensino de literatura era trabalhado de forma quase inexistente, sem ser privilegiado o bastante no planejamento das professoras. O que ocupava a maior parte das aulas de Língua Portuguesa era o ensino puramente normativo da língua, ou seja, a gramática.

Após essa constatação, partimos para a pesquisa e seleção de textos de autores maranhenses que instigassem a formação do pensamento crítico, trabalho este que ocupou os meses de dezembro/2016 e janeiro/2017. Optamos por trabalhar com o gênero lírico e selecionamos oito poemas de autores maranhenses do século $X X$, dentre modernos e contemporâneos (em anexo). Utilizamos os meses de fevereiro e março/2017 para o planejamento das aulas e confecção dos materiais didáticos, sempre tendo em mente que o objetivo maior é ministrar aulas críticas de Literatura em forma de oficinas. Foram elaboradas cinco aulas de 100 minutos cada e essas aulas ocorreram nos meses de abril e maio/2017 em uma turma de $2^{\circ}$ ano do Ensino Médio na referida escola.

Uma de nossas preocupações, pelo fato de trabalharmos com o gênero lírico, era como seria feita a leitura e interpretação de um poema pelos alunos. Será que eles tinham o hábito de ler poemas? Se sim, como o faziam? Pois sabemos que há certos elementos centrais no processo de leitura a se considerar. Esses e outros questionamentos pairavam em nossas cabeças constantemente.

Resolvemos tentar solucionar todas essas questões e iniciamos procurando saber a história de leitura dos alunos, que segundo Cosson (2014, p.37) caracterizase com a seguinte preocupação:

Uma história da leitura se preocupa usualmente com o contexto, representado pela circulação dos textos ou pelos hábitos sociais dos leitores, enquanto a psicolinguística se ocupa preferencialmente do leitor ou do processo cognitivo da leitura, pode-se estabelecer um percurso quase cronológico para o posicionamento de cada elemento no circuito da leitura.

Dessa forma, partindo do pensamento de Cosson, primeiramente selecionamos poemas que trouxessem uma temática que fizesse parte do cotidiano dos alunos e que fosse de uma linguagem clara para que a leitura fluísse sem nenhum 
empecilho e para que o poema fosse, sobretudo, de interpretação compreensível. Nosso foco não era explorar a leitura de forma tradicional - que nada mais é do que apenas repetir o que já foi dito pelo autor sem nenhuma contextualização e sem nenhuma visão crítica.

É importante lembrar que para ministrar as aulas utilizamos a sequência básica sugerida por Cosson (2006, p.51): motivação, introdução, leitura e interpretação. O autor propõe esse passo a passo como forma de sistematizar a aula de literatura, pois é necessário planejá-la de forma consciente.

A primeira aula foi ministrada no dia 24/04/2017 e teve como conteúdo a exibição do filme Muleque té doido 1 (2013), cujo objetivo principal era apresentar a cultura maranhense retratada lá. Denominamos esta aula de motivadora e por isso notamos que os alunos foram flexíveis, abraçando o projeto de imediato, até porque esse era o intuito deste primeiro encontro: motivar e estimular o desejo de conhecer a cultura maranhense. Nessa primeira aula fizemos uma pequena introdução ao universo cultural do Maranhão, o que nos serviu para confirmar a hipótese de que esse era um assunto que os alunos pouco dominavam.

A segunda aula aconteceu no dia 02/05/2017 e ela também teve a característica de aula motivadora: neste encontro foi realizada uma roda de conversa em que fizemos um debate pós-filme. O objetivo era fazer com que os alunos associassem a cultura maranhense explorada no filme com a cultura timonense à qual eles estão inseridos. $A$ discussão foi ganhando ritmo à medida em que todos participavam. Utilizamos um roteiro que possuía alguns questionamentos, tais como: 1 - Quais fatores específicos vocês conseguiram identificar na cultura maranhense? 2- Como se dá o modo de falar dos maranhenses? Nesse momento eles começaram a citar "palavras/gírias" do filme que já conheciam e que fazem parte do vocabulário deles; já as que eles não conheciam disseram que iriam começar a usar. Foi nesse momento que pudemos perceber o quanto os alunos queriam se sentir pertencentes à cultura maranhense de fato.

Ainda nesta aula do dia 02/05/2017, questionamos se eles conseguiam identificar as lendas que foram exploradas no filme; para tanto, fizemos uma discussão sobre as lendas e perguntamos: 3- Quais lendas vocês conhecem? Todas as lendas que eles citaram eram piauienses. Para nós, executores do projeto, esta atitude configurou-se como um choque cultural. Os alunos sabem que as lendas são parte essencial de uma cultura e demonstraram conhecer muito pouco da cultura maranhense, pois até o momento da exibição do filme não conheciam nenhuma lenda 
que faz parte da cultura do Maranhão como um todo. Algumas lendas apresentadas no filme - como a lenda de Ana Jansen - só foram conhecidas a partir daquele instante. Por fim, pedimos que os alunos destacassem as diferenças entre as cidades de São Luís e Timon, o que nos certificou da aproximação e vivência maior deles com a cultura piauiense.

Percebemos, portanto, que as duas primeiras aulas ministradas pertencem à etapa da motivação de uma aula de literatura, conforme sugere o passo a passo metodológico de Cosson (2006). As aulas seguintes abarcaram as etapas de introdução, leitura e interpretação, pois em cada uma delas abordou-se um poema diferente. A introdução consistia na apresentação do poema que seria trabalhado/lido, justificando a escolha do texto e do autor, proporcionando algumas informações ou curiosidades sobre o livro ou sobre o autor de forma breve, apenas para aguçar os sentidos dos alunos.

Já a leitura dos poemas era feita primeiramente pelos alunos de forma individual e sem empecilhos, para que ao final eles sempre emitissem as suas opiniões. A interpretação é o momento pós-leitura, no qual é feita a construção de sentido do texto a partir do ponto de vista do aluno, de seu repertório de leitura, e, sobretudo sobre suas vivências. É nessa etapa que acontecem os debates em que a turma compartilha e troca ideias. Vamos descrever como as aulas seguintes aconteceram.

A terceira aula, realizada no dia $08 / 05 / 2017$, foi dividida em dois momentos: iniciamos com a apresentação de um esquema com todas as áreas que compõe a cultura de um povo de um lugar, mas nesse caso a cultura do Maranhão. Essa apresentação foi feita através de imagens/slides e procurando sempre instigar o pensamento crítico com questionamentos e sempre os colocando dentro de uma conversa. O segundo momento foi um pouco mais descontraído: os alunos fizeram um círculo para a leitura do poema São Luís da poeta Dagmar Desterro (BRASIL,1994, p.152-153). O poema traz consigo uma descrição particular da cidade de São Luís e que ao mesmo tempo se confunde com as lembranças da poeta.

Primeiro os alunos fizeram uma leitura e análise individual e depois eles expuseram as suas opiniões, suas análises e consequentemente seguimos para o debate, mas sempre fazendo com que despertassem o pensamento crítico por meio da indagação norteadora: Se moramos em Timon e Timon faz parte do estado do Maranhão por que não nos sentimos pertencentes a essa cultura? Depois dessa 
indagação, trabalhamos para que eles se sentissem pertencentes e ao mesmo tempo criassem uma identidade cultural; as opiniões deles foram essenciais para a construção dessa identidade. A aula foi encerrada com uma breve apresentação da poeta Dagmar Desterro e sua importância para a cultura e a literatura maranhense.

A quarta e penúltima aula aconteceu no dia 16/05/2017. Optamos por fazer uma roda de poesia e foi distribuído um poema para cada aluno. Selecionamos o poema do poeta Ferreira Gullar intitulado João Boa Morte - cabra marcado pra morrer (BRASIL,1994, p.207-208). Diferente de tudo que já tínhamos discutido nas aulas anteriores, o texto possui uma forte crítica social pois sua temática se volta para a denúncia de injustiças praticadas na sociedade nordestina e que induzem à opressão do homem. Um aluno pediu para recitar o poema e outro aluno pediu para dar início ao debate, expondo a sua opinião e análise; em seguida, todos começaram a expressar seus pontos de vista, uns parecidos, outros nem tanto.

Para conseguirmos interpretar o poema fizemos a seguinte pergunta: Qual o tema do poema? Mais uma vez a leitura foi feita em voz em alta e chegamos ao consenso que a temática se voltava para a "liberdade de expressão". Observamos seu contexto histórico e nos deparamos com a sociedade dos últimos anos da década de 1960 pois poema foi escrito durante a ditadura militar no Brasil, e por isso possui uma linguagem contundente e feroz.

A discussão foi trazida para os dias atuais e os alunos começaram a fazer um paralelo entre a sociedade retratada no poema e a sociedade atual. Foi o debate mais proveitoso de todos, em que os alunos discutiram constantemente. Nesse momento pudemos perceber que o pensamento crítico estava inserido na emissão de cada discurso. Também notamos que essa aula mexeu com eles e os incomodou, haja visto que todos ali estudavam em uma escola militar e exerceram a crítica a esse modelo de escola. A esta altura do projeto, mostramos que a poesia era o primeiro passo para a melhor percepção das coisas, da sociedade e da vida, pois essa é a função da literatura. A aula foi encerrada com a apresentação da vida e obra do poeta Ferreira Gullar, destacando a sua importância para ambas literaturas maranhense e brasileira.

A quinta e última aula foi ministrada no dia 23/05/2017. Quando chegamos à sala, os alunos já estavam organizados em círculos e os poemas foram entregues. $\mathrm{O}$ texto selecionado foi o poema da poeta contemporânea Dilercy Adler, intitulado Negação de si (BRASIL,1994, p.297). A leitura do poema foi feita por uma menina que o declamou de forma desprendida, solta e em alto e bom som. Após a leitura, a aluna 
fez a análise de forma bem crítica. Questionamos sobre o tema do poema e algumas alunas e alunos disseram que era o feminismo e esses mesmos se autodenominaram como feministas. Fizemos a análise do poema todo começando com o título, que já é sugestivo; descrevemos a mulher do poema por meio das imagens poéticas que o texto nos dá e dessa forma eles exercitaram a imaginação.

Com toda a extensão do debate trouxemos o poema para os dias atuais e um dos alunos emitiu o seguinte discurso: "Que a própria mulher não se dá o devido valor e nem o respeito quando está vestida com roupas muito curtas." Uma das alunas se sentiu ofendida e a turma toda concordou com ela, e logo estavam defendendo a condição de liberdade da mulher. O debate foi retomado e uma das alunas falou: "Professora, apesar de estarmos em uma sociedade um tanto moderna, podemos perceber que o pensamento machista ainda está em vigor em todos os ambientes". A partir desta colocação, o debate prosseguiu e discutimos sobre liberdade da mulher, feminismo, sexualidade e relações de gênero. Esses temas deixaram as meninas inquietas pois elas estavam sempre defendendo o seu ponto de vista. Foi uma aula muito produtiva e ao final destacamos a importância da poeta Dilercy Adler bem como seu lugar no cenário literário maranhense contemporâneo.

Como sabíamos que a aula seguinte seria a finalização do projeto, propusemos que os alunos produzissem textos, poéticos ou em prosa, explorando à sua maneira uma das temáticas debatidas anteriormente e os apresentassem no dia da culminância. Esta última aula ocorreu no dia 06/06/2017 e os alunos trouxeram contos, lendas e poemas de sua autoria. Entendemos que produzir textos também é uma forma de leitura, pois temos que ler o mundo para podermos escrever e temos que escrever para aprender a ler o mundo.

\section{Considerações finais}

O objetivo maior do projeto foi alcançado satisfatoriamente, haja vista que queríamos ampliar, por meio da leitura e interpretação de textos, o poder de argumentação crítica oral e escrita de alunos do Ensino Médio da rede estadual do município de Timon - MA através da leitura, o que para Cosson (2014, p.27) é antes de qualquer coisa, um processo de decifração do texto, de decodificação daquilo que o texto diz. 
Foi através desse processo de decodificação que conseguimos introduzir a leitura na vida daqueles garotos e garotas, sem nenhuma concepção teórica, apenas aguçando o senso crítico e sem descartar as bagagens que os alunos possuem. Alguns questionamentos podem surgir, principalmente as que dizem respeito a como mensurar se o objetivo foi alcançado. Sabemos que foi alcançado positivamente, uma vez que no decorrer das aulas eles (os alunos) foram ficando cada vez mais inquietos e mais críticos e já estavam se sentindo pertencentes à cultura maranhense e tudo isso por meio do texto literário, o qual tem a capacidade de mudar o olhar sobre o mundo - pessoas e coisas.

No desenvolvimento desse projeto, que perfez o período de quase um ano, pudemos constatar, com a contribuição de alguns teóricos, que a literatura não é somente uma arte em que o texto serve exclusivamente para ser apreciado e confrontado com características de alguma estética literária. Constatamos que seu ensino deve ter maior relevância para os alunos, deve caminhar como uma instituição reveladora de cultura e valores ligados à função social que o texto possui; seu ensino pode e deve proporcionar a formação de indivíduos mais atuantes e críticos, construindo, assim, cidadãos.

Ressignificar as aulas de literatura por meio da escolha do gênero lírico contribuiu para que se desmitificasse a dificuldade de interpretação de poemas, e resultou no debate amplo de temas atuais, como a importância da cultura de um povo, o direito à liberdade de expressão e a força da mulher na sociedade. Dessa forma percebemos que, ao final do projeto, os alunos já refletiam um pensamento mais maduro e com um senso crítico aguçado.

Concluímos o projeto com a sensação do dever cumprido e de poder retornar à sociedade de forma prática todo o conhecimento teórico obtido na universidade. Dificuldades na prática docente sempre iremos encontrar e, com o ensino de literatura não é diferente, mas se procurarmos conhecer e adotar experiências de outros colegas e/ou estudiosos da área que tenham obtido bons resultados, o trabalho do professor pode ter significativos rendimentos. Para tanto, é necessário que este profissional reflita sobre seu próprio modo de ensinar e sobre sua própria prática enquanto leitor. Desta forma, ele estará contribuindo para formar cidadãos conscientes de sua prática e formar leitores críticos que ampliem seus horizontes emocionais, intelectuais, culturais e sociais por meio da leitura literária. 


\section{Referências bibliográficas}

BAPTISTA, A. M. H. Educação, ensino \& literatura: propostas para reflexão. São Paulo: Arte-Livros Editora, 2012.

BRASIL, A. A poesia maranhense no século XX. Rio de Janeiro: Imago/ São Luís, MA: SIOGE, 1994.

CÂNDIDO, A. Vários Escritos. Rio de Janeiro: Ouro sobre Azul, 2011.

CORREAA, D. M. Da literatura maranhense: o romance do século $X X$. São Luís:

EDUEMA, 2015.

COSSON, R. Letramento Literário: teoria e prática. São Paulo: Contexto, 2006.

COSSON, R. Círculos de leitura e letramento literário. São Paulo: Contexto, 2014. JOUVE, V. Por que estudar literatura? São Paulo: Parábola, 2012.

LEAHY-DIOS, C. Educação literária como metáfora social: desafios e rumos. São Paulo: Martins Fontes, 2004.

MAGNANI, M. do R. M. Leitura, literatura e escola: sobre a formação do gosto. São Paulo: Martins Fontes, 2001

MULEQUE TÉ DOIDO 1: disponível em <https://www.youtube.com/watch?v=wjQyMgbCNnA> (acesso em 14/10/2017) Duração: 1h 55min 